\title{
IN VITRO ANTICANCER AND ANTI-LIPOXYGENASE ACTIVITIES OF CHIA SEED OIL AND ITS BLENDS WITH SELECTED VEGETABLE OILS
}

\section{RAMZI ABDULRASHED ABDULKHALEQ GAZEM, HONNALAGERE RAMESH PUNEETH, CHAKKERE SHIVMADHU MADHU, ANGATAHALLI CHANDRASHEKARAIAH SHARADA*}

Department of Biochemistry, Yuvaraja's College, University of Mysore, Mysuru - 570 005, Karnataka, India. Email: sharadaac@gmail.com Received: 28 April 2017, Revised and Accepted: 16 June 2017

ABSTRACT

Objective: To investigate the anticancer and anti-inflammatory potential of chia seed oil (CSO) and its blends in vitro.

Methods: The in vitro cancer cytotoxic properties ability of CSO and its blends was evaluated by (3-(4,5-dimethylthiazol-2-yl)-2,5-diphenyltetrazolium bromide) (MTT) and trypan blue assays using major cell lines including chronic myelogenous leukemia, HeLa and MCF-7 cells. The anti-inflammatory effect of the CSO and its blends was studied by assessing the anti-lipoxygenase (LOX) activity in vitro.

Results: Incubation with CSO alone significantly inhibited the LOX activity. In the combination groups, CSO slightly increased the inhibition among blends of soybean and palmolein oils. In addition, CSO alone and in blends demonstrated potent and differential anticancer activity in MTT and trypan blue assays.

Conclusion: Our results pave the way for the conclusion that CSO alone or in combination with the vegetable oils proves to be a healthy synergistic supplement or an adjuvant for the current diet. The supplementation with CSO is suggested for the modern lifestyle to delay or prevent the incidence of degenerative disorders.

Keywords: Salvia hispanica, Trypan blue, (3-(4,5-dimethylthiazol-2-yl)-2,5-diphenyltetrazolium bromide), Inflammatory.

(c) 2017 The Authors. Published by Innovare Academic Sciences Pvt Ltd. This is an open access article under the CC BY license (http://creativecommons. org/licenses/by/4. 0/) DOI: http://dx.doi.org/10.22159/ajpcr.2017.v10i10.19450

\section{INTRODUCTION}

Unmitigated increase in the incidence of cancer and the incomplete success with the chemotherapy has presented the lookout for an effective but safer anticancer drug. The past decades have assessed the dietary role for modern diseases and indicated a strong relationship between the diet and the ailment via both population studies and experimental reports. Specific dietary designs have been proposed for various ailments among different human communities. Hence, different sources for the known dietary principles have been hunted for in the recent past which provides an economic and efficient supply of the same $[1,2]$.

Although plenty of drugs were explored for cancer treatment, the clinical relevance of drug development for a routine practice remains distant due to the high costs and side effects. Inflammation dictates the initiation and progression. The $\mathrm{n}-3$ fatty acids demonstrate antiinflammatory effects in vivo. However, there is a limitation of data about the cancer preventive role of fatty acids however they have been demonstrated to preserve the muscle mass and function in chemotherapeutic subjects [3]. The n-3 fatty acids like eicosapentaenoic acid and docosahexaenoic acids have been found to reduce the risk of breast cancer [4]. A new concept of a combination of chemotherapy and nutrition therapy is emerging.

Polyunsaturated fatty acids have been claimed to enhance the membrane dynamics. Hence, the concentration of the former is usually associated with the mitochondrial function. Several reports suggest a strong anticancer property for polyunsaturated fatty acid (PUFA) in vivo and in vitro [5]. Accordingly, we selected chia (Salvia hispanica) a vegetarian PUFA source and set out to study its biological properties using the accepted in vitro models.
In this line of research, various plant products and their derivatives have been screened for their biological activities including anticancer properties [6-21]. We have reported the chemical constituents and fatty acid profile of chia seed oil (CSO). Further, we also assessed antidiabetic, antioxidant, and anti-inflammatory properties of CSO alone and in blend with the major vegetable oils. Our studies were suggestive that CSO reduces the preliminary complications of diabetes as well as reduces the proinflammatory reactions [8,9]. Hence, our hypothesis is that owing to the major biological properties; chia seed can be a potent anticancer agent. We estimated the cancer cytotoxic properties of CSO and its blends with the major vegetable oils among the major cancer cell lines for testing the hypothesis.

\section{MATERIALS AND METHODS}

\section{Materials}

Seeds of chia (S. hispanica L.) were procured locally from Heggadadevana Kote, Mysuru, Karnataka, India. The sample was authenticated by the Department of Studies in Botany, Manasagangotri, Mysuru. The seeds were cleaned to get rid of impurities/damaged seeds; stored at $4^{\circ} \mathrm{C}$. The sound seeds were powdered, and the oil was extracted [9] and used for the analysis. The selected vegetable oils such as sunflower oil (SFO), olive oil (OlO), palmolein oil (PO), and soybean oil (SO) were purchased from local market in Mysuru city, Karnataka.

\section{Chemicals and reagents}

All solvents, chemicals, and drugs used in the studies were of analytical grade and purchased from SDFCL, Mumbai, India. Tris buffer, linoleic acid was purchased from SRL, India.

\section{Sample preparation}

The blends were prepared using raw CSO with selected vegetable oils, namely, PO, soybean, and OlO. These blends were prepared by placing 
them in a test tube in the desired ratio and mixing in a cyclomixer for 15 minutes at room temperature. The oil blends were screened for the biological activities immediately. The mixtures of oil samples of different concentrations S1-S14 (10-40 $\mu \mathrm{l} / \mathrm{ml})$ were prepared in DMSO (10\%) and sample preparation was as following: Sample 1-(SFO), Sample 2-(CSO), Sample 3-(OlO), Sample 4-(PO), Sample 5-(SO), Sample 6-(CSO: OlO [75:25]), Sample 7-(CSO: OlO [50:50]), Sample 8-(CSO: OlO [25:75]), Sample 9-(CSO: PO [75:25]), Sample 10-(CSO: PO [50:50]), Sample 11-(CSO: PO [25:75]), Sample 12-(CSO: PO [75:25]), Sample 13(CSO: SO [50:50]), and Sample 14-(CSO: SO [25:75]).

\section{Cell lines and culture}

Human chronic myelogenous cell lines (CM cells), MCF-7 (human breast tumour), and HeLa (human cervical cancer) obtained from the National Centre for Cell Science, Pune, India. Cells were grown in RPM1 1640 supplemented with $10 \%$ heat-inactivated fetal bovine serum, $100 \mathrm{U} / \mathrm{ml}$ of penicillin and $100 \mu \mathrm{g}$ of streptomycin $/ \mathrm{ml}$ and incubated at $37^{\circ} \mathrm{C}$ in a humidified atmosphere with $5 \% \mathrm{CO}_{2}$. The standard drugs used for the cells are CM cells - abitrexate; MCF-7 - tamoxifen, and HeLa - avastin.

\section{Methods}

\section{In vitro anti-lipoxygenase (LOX) activity}

LOX enzyme was prepared as a crude extract from pre-soaked soybeans by homogenizing in phosphate buffer, $\mathrm{pH} 6.8$ for 20 minutes at $4^{\circ} \mathrm{C}$ and centrifuged at $10,000 \mathrm{rpm}$ for 10 minutes at $4^{\circ} \mathrm{C}$ and supernatant was used [18]. Aliquots of crude LOX extract were incubated for 5 minutes (in $50 \mathrm{mM}$ Tris buffer, $\mathrm{pH}$ 7.4) with oil samples in triplicates at different concentrations $(10,20$, and $40 \mu \mathrm{l})$. Simultaneously, separate aliquots of enzyme were incubated with indomethacin (standard) and the oil samples. The enzyme reaction was started by adding $1 \mathrm{ml}$ of linoleic acid $(50 \mu \mathrm{M})$. Increase in absorbance was recorded at $234 \mathrm{~nm}$ using a spectrophotometer against buffer blank. One unit of enzyme was taken as equivalent to the amount of enzyme that generated an increase in absorbance of 1.0 per minutes at $234 \mathrm{~nm}$.

\section{In vitro anticancer studies}

3-(4, 5 dimethyl-2-yl)-2,5 diphenyl tetrazolium bromide (MTT) assay The cytotoxic effects of the different oil samples (S1-S14) were assessed against the $\mathrm{CM}$ leukemic cells $\left(5 \times 10^{5}\right.$ cells $)$ using MTT assay [19]. The test samples are dissolved in DMSO and treated with different concentrations of oil samples $(10,20$, and $40 \mu \mathrm{l})$. Cells in the control wells received the same volume of medium containing DMSO. After 48 hrs treatment, cells were harvested and incubated with MTT $(0.5 \mu \mathrm{g} / \mathrm{ml})$ for $4 \mathrm{hrs}$ at $37^{\circ} \mathrm{C}$ in 96 well plate. The blue MTT formazan precipitate formed in the viable cells is solubilized by the addition of $70 \mu \mathrm{l}$ DMSO. The suspension is placed in micro vibrator for 5 minutes, and absorbance was measured at $540 \mathrm{~nm}$ using a multimode reader (Varioskan Flash Multimode, Thermo Scientific, USA). The experiment was performed in triplicate and repeated at least for 3 times. $\mathrm{IC}_{50}$ concentration for each oil sample using the Prism software.

\section{Trypan blue exclusion assay}

To study the growth suppressive effects of the oil samples $\left(\mathrm{S}_{1}-\mathrm{S}_{14}\right)$, $0.5 \times 10^{5}$ cells $/ \mathrm{ml}$ were plated in a 24 well plate (Corning, USA.) in $1 \mathrm{ml}$ of complete medium [19]. The cells were treated with various concentrations of the oil samples $(10,20$, and $40 \mu \mathrm{l} / \mathrm{ml})$. DMSO treated cells were used as a control. Cells were harvested after $48 \mathrm{hr}$ and stained with $0.4 \%$ trypan blue and calculated using a hemocytometer for viable cells. Experiments were done in triplicates, and the percentage of growth inhibition by different samples at different concentrations was plotted against time ( $48 \mathrm{hr})$.

\section{Statistical analyses}

The data obtained were analyzed by one-way ANOVA followed by Tukey's post-hoc analyses using the Graphpad software prism 5.1 and Excel software at constant $p \leq 0.05$. The data were expressed as a mean \pm standard deviation, and all experiments were compared with control and performed in triplicates.

\section{RESULTS AND DISCUSSION}

Many experimental evidence suggests that inflammatory pathways predominate the pathophysiology of major metabolic syndromes such as diabetes and cardiovascular diseases (CVD). It has been noted that obesity and comorbidities such as diabetes and CVD are resulted from chronic, low-grade inflammation impacting multiple organ systems [22]. The compromised inflammatory state is usually attributed to higher levels of proinflammatory signaling from adipocytes. Dietary intervention studies have indicated that n-3 PUFA rich diet alleviates the metabolic syndromes through attenuating the inflammatory status of the system $[23,24]$. Hence, it was interesting to study the anti-inflammatory properties of Indian chia seeds in an in vitro setup. Even though chia is not used as a major food component in today's diet globally, owing to the high content of alpha linolenic acid (ALA), chia is speculated to become an excellent dietary adjuvant shortly. Hence, in this study, we fortified chia oil with the other major edible vegetable oils such as PO, OlO, and SO for the anti-inflammatory assays. It was assumed that fortification with the other edible oils may replicate the changes in the beneficial effects of CSO when it is used in association with the regular diet [25]. Fortification with the other vegetable oils is a mandatory method of activity assessment in case of not so frequently used food products like chia since this method reveals the complementary effects of these dietary components [26]. In this study, we examined the anti-inflammatory property of CSO per se and in synergy with the other vegetable oils employing in vitro LOX assay.

\section{In vitro anti-LOX activity}

The anti-inflammatory property of CSO was assessed by estimating inhibition of LOX activity in vitro (Fig. 1). Enzymes like LOX actively participate in the inflammatory reactions in vivo. These are autocatalytic enzymes which are activated by numerous factors. Therefore, studying the inhibitory effects on LOX reveal a better picture of the biological activity of the oil blends. For this purpose, the crude extract of LOX was prepared from soybeans. Incubation with CSO alone significantly inhibited the LOX activity in a concentrationdependent manner (up to 63\%). The LOX inhibitory properties of the other oils individually were not different than that of CSO. However, in combination groups, CSO slightly increased the inhibition among blends of soybean and PO.

Previous reports suggest that blending of different oils resulted in better storage and improved antioxidant properties in vitro [27]. Moreover, health benefits from functional foods as chia seeds are usually conspicuous on a chronic supplementation. The results of our study are in contrast with a few reports about anti-inflammatory properties of ALA and CSO among in vivo systems.

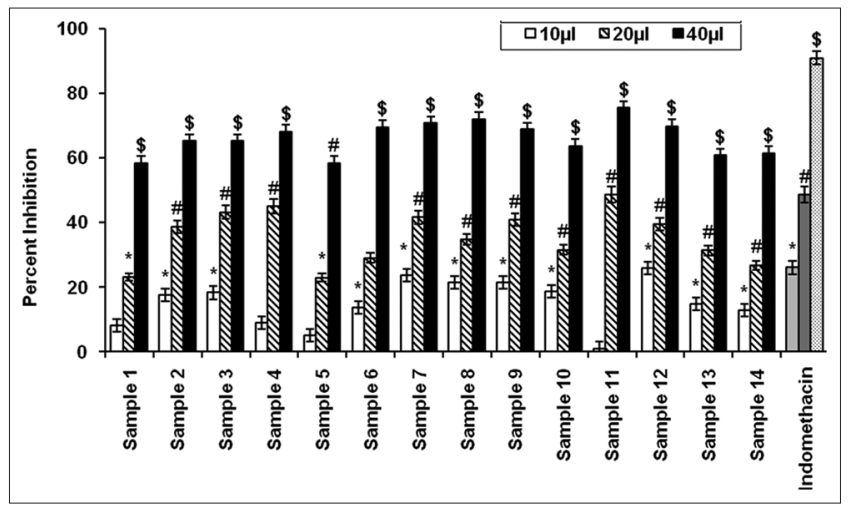

Fig. 1: Effects of oil samples on the activity of lipoxygenase in vitro. Values are mean \pm standard deviation $(n=3$ replications for each sample and concentration) analyzed by one-way ANOVA followed by post -hoc Tukey's test. Data are pooled from three independent experiments $(*, \#$ and $\$$ indicate significant difference at $p \leq 0.05)$ 
In vitro anticancer property against $\mathrm{CM}$ leukemic cells

MTT is a most accepted assay to estimate the viability of the cells in vitro [28]. Among all the oil samples tested for anticancer effect, chia oil demonstrated highest cytotoxic efficacy (up to 90\%) followed by olive and SOs (Fig. 2) against the human CM cells. The $\mathrm{IC}_{50}$ of CSO was $5.32 \mu \mathrm{l}$ (Table 1) which was slightly increased in the blends of palmolein and SOs (up to $12.07 \mu \mathrm{l}$ ). Although comparatively the cytotoxic effects of PO was marginally lesser when compared to other oil samples, but in combination with CSO, the cytotoxic property was enhanced. Similar results were observed among SO alone and blend with chia oil. Contrast to MTT assay, in trypan blue assay; the oil samples demonstrated a slightly different trend of anticancer activity (Fig. 3). Based on trypan blue assay, CSO alone inhibited CM cells proliferation significantly (up to 67\%), and this effect was similar to $\mathrm{OlO}$ alone. Palmolein and SOs individually did not affect the cancer cells. However, CSO in blending with PO and SO the anticancer activity was observed up to $50 \%$. As evidenced from the data, the enhanced anticancer activity among these blends is totally owed to CSO.

In vitro anticancer property against HeLa cells

Further, the cytotoxic property of CSO alone and in combinations was assessed in HeLa cells also. HeLa cells are the human cervical cancer

Table 1: $\mathrm{IC}_{50}$ concentrations of oil samples $(\mu \mathrm{l})$ and standard drug compounds (ng) calculated from the MTT assay among the cancer lines

\begin{tabular}{llll}
\hline Samples & CM cells & HeLa cells & MCF-7 cells \\
\hline Sample 1 & $9.90 \pm 0.10$ & $15.06 \pm 0.15$ & $31.53 \pm 0.32$ \\
Sample 2 & $5.32 \pm 0.05$ & $11.46 \pm 0.11$ & $17.24 \pm 0.17$ \\
Sample 3 & $9.71 \pm 0.10$ & $72.46 \pm 0.72$ & $103.00 \pm 2.41$ \\
Sample 4 & $49.50 \pm 0.50$ & $167.79 \pm 0.68$ & $510.00 \pm 5.00$ \\
Sample 5 & $13.75 \pm 0.14$ & $126.26 \pm 1.26$ & $252.00 \pm 2.50$ \\
Sample 6 & $5.56 \pm 0.06$ & $18.70 \pm 0.19$ & $64.94 \pm 0.65$ \\
Sample 7 & $11.51 \pm 0.12$ & $20.33 \pm 0.20$ & $110.00 \pm 1.00$ \\
Sample 8 & $12.07 \pm 0.12$ & $23.35 \pm 0.23$ & $511.00 \pm 5.00$ \\
Sample 9 & $5.82 \pm 0.06$ & $30.30 \pm 0.30$ & $33.78 \pm 0.34$ \\
Sample 10 & $5.82 \pm 0.06$ & $61.32 \pm 0.61$ & $79.62 \pm 0.80$ \\
Sample 11 & $11.11 \pm 0.11$ & $126.26 \pm 1.26$ & $257.00 \pm 2.50$ \\
Sample 12 & $6.35 \pm 0.06$ & $24.18 \pm 0.24$ & $26.23 \pm 0.26$ \\
Sample 13 & $6.04 \pm 0.06$ & $39.23 \pm 0.39$ & $45.60 \pm 0.46$ \\
Sample 14 & $15.63 \pm 0.16$ & $57.06 \pm 0.57$ & $72.46 \pm 0.72$ \\
Standard & $10.42 \pm 0.10$ (ng) & $10.20 \pm 0.10(\mathrm{ng})$ & $10.31 \pm 0.10$ (ng) \\
drug & & & \\
\hline Valys aremeantSD (cal & & &
\end{tabular}

Values are mean \pm SD (calculated from three independent

experiments using the Prism software). SD: Standard deviation,

MTT: (3-(4,5-dimethylthiazol-2-yl)-2,5-diphenyltetrazolium bromide),

CM: Chronic myelogenous

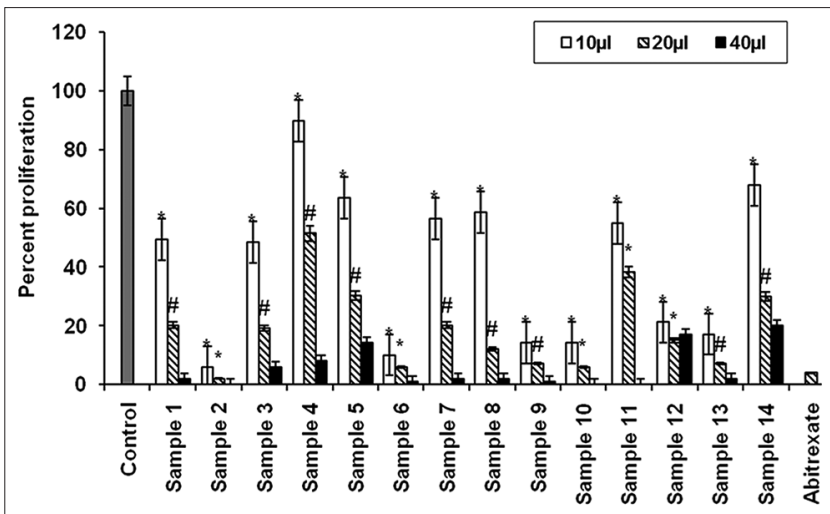

Fig. 2: Effects of oil samples against viability (or proliferation) of human chronic myelogenous leukemic cells in vitro (48 hr exposure). Values are mean \pm standard deviation $(n=3$ replications

for each sample and concentration) analyzed by one-way ANOVA followed by post-hoc Tukey's test. Data are pooled from three independent experiments $(*$, \# and \$ indicate significant difference at $\mathrm{p} \leq 0.05$ cells and are typical of their kind. HeLa cells are the oldest used humanderived cancer cells for the research purpose. These cells are widely employed to assess the anticancer activity of possible potential drug compounds [29]. In addition, these cells are also employed to study the mechanistic pathways of those active principles. As anticipated, CSO per se significantly inhibited proliferation of HeLa cells as evidenced by the MTT assay (Fig. 4). The IC ${ }_{50}$ ofCSO was $11.46 \mu$ (Table 1). Interestingly, the cytotoxic effects were similarly significant in combination groups with OlO, however, was not up to the extent of CSO alone. Further, though individually palmolein and SO did not demonstrate anticancer activity, but in combination with CSO, they showed significant inhibition of cancer cell proliferation. The $\mathrm{IC}_{50}$ concentration of olive, palmolein and SOs individually were $72.46,167.79$, and $126.26 \mu \mathrm{l}$, however, the values decreased significantly in combination with the chia oil in their blends and were $18.7,30.3$, and 24.18 , respectively (Table 1 ). In addition, the trypan blue assay confirmed the results obtained in MTT assay. In trypan blue assay, CSO alone inhibited HeLa cell proliferation significantly (Fig. 5). In combination, chia oil enhanced the activity of palmolein and SO marginally. Evidently, the results obtained from trypan blue assay were similar to that of MTT assay.

\section{In vitro anticancer property against MCF-7 cells}

The anticancer activity of CSO was confirmed using the breast cancer cells, namely, MCF-7. The MCF-7 breast cancer cells represent the metastatic cells with the highest virulence and are experimentally

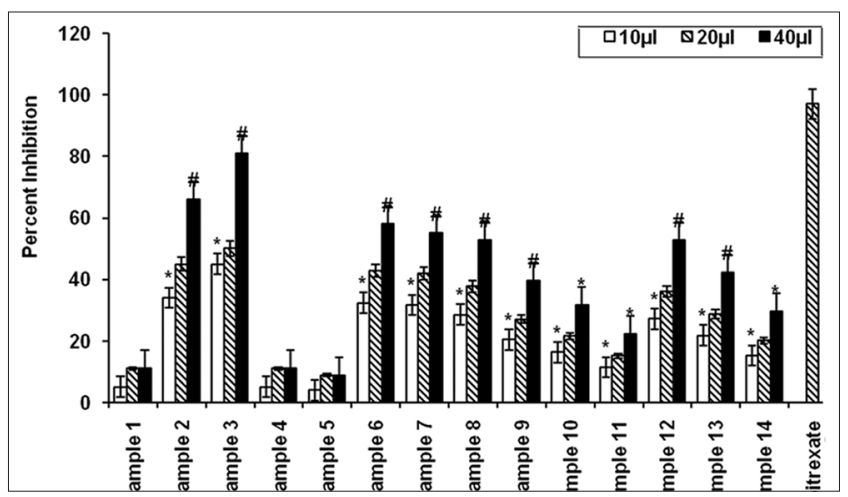

Fig. 3: Effects of oil samples against human chronic myelogenous leukemic cells in vitro (trypan blue exclusion method). Values are mean \pm standard deviation $(n=3$ replications for each sample and concentration) analyzed by one-way ANOVA followed by post-hoc Tukey's test. Data are pooled from three independent experiments ( $*$, \# and $\$$ indicate significant difference at $p \leq 0.05$ )

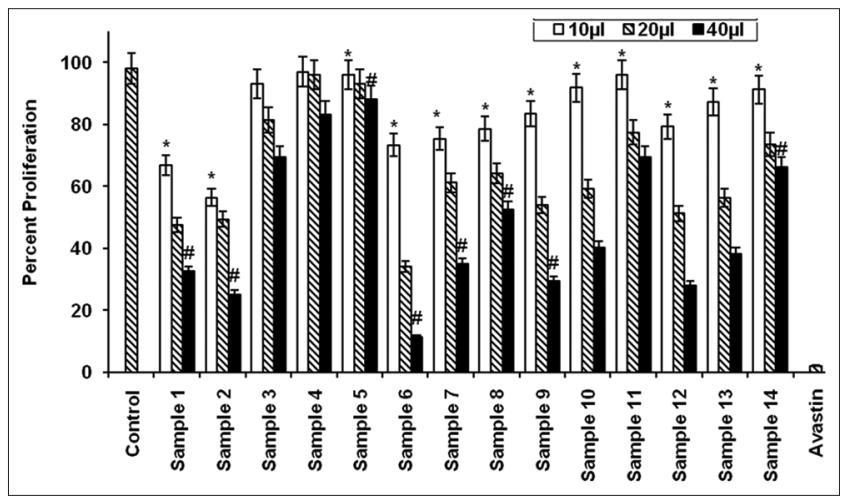

Fig. 4: In vitro anticancer effects of oil samples against HeLa cells ( $48 \mathrm{hr}$ exposure). Values are mean \pm standard deviation ( $n=3$ replications for each sample and concentration) analyzed by one-way ANOVA followed by post-hoc Tukey's test. Data are pooled from three independent experiments $(*, \#$ and $\$$ indicate significant difference at $\mathrm{p} \leq 0.05$ ) 


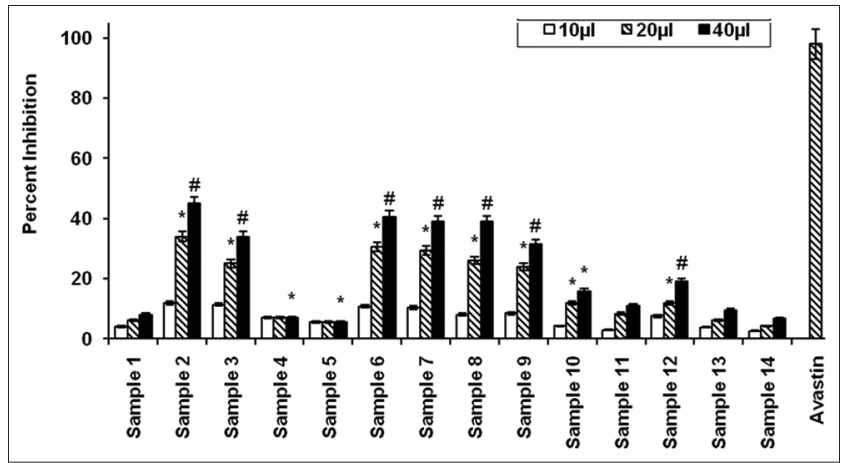

Fig. 5: Cytotoxic effects of oil samples against HeLa cells in vitro ( $48 \mathrm{hr}$ exposure, trypan blue exclusion method). Values are mean \pm standard deviation $(\mathrm{n}=3$ replications for each sample and concentration) analyzed by one-way ANOVA followed by post-hoc Tukey's test. Data are pooled from three independent experiments $(*, \#$ and $\$$ indicate significant difference at $\mathbf{p} \leq 0.05)$

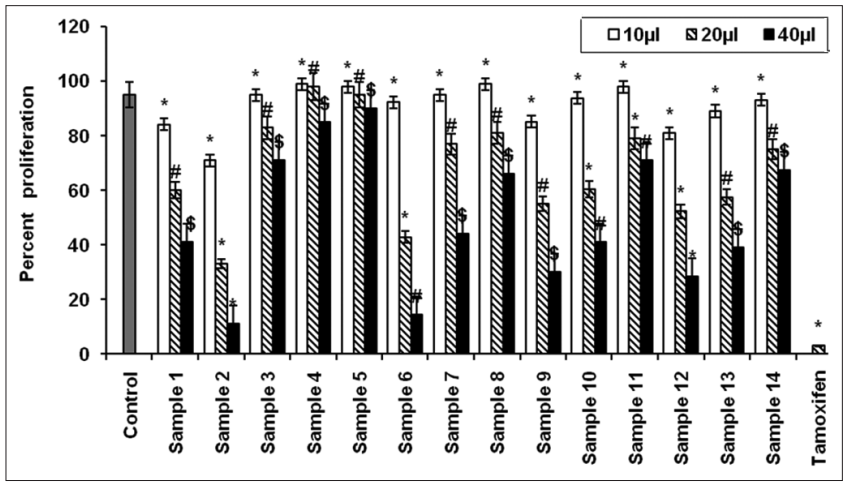

Fig. 6: Anticancer effects of oil samples against MCF-7 cells in vitro ( $48 \mathrm{hr}$ exposure). Values are mean \pm standard deviation $(\mathrm{n}=3$ replications for each sample and concentration) analyzed by one-way ANOVA followed by post-hoc Tukey's test. Data are pooled from three independent experiments $(*, \#$ and $\$$ indicate significant difference at $\mathbf{p} \leq 0.05$ )

exploited to study the mechanism of action of the drug candidates [29]. There was a significant and concentration-dependent inhibition of cancer proliferation among cells exposed to CSO per se (Fig. 6). The protective effects were significant in $\mathrm{OlO}$ combination groups (with $75 \%$ chia oil). Individually palmolein and SO did not show protective efficacy. However, in combination groups, there was a slight anticancer activity among palmolein+chia and SO+chia oil. The IC $_{50}$ of CSO was $17.24 \mu \mathrm{l}$ (Table 1). The $\mathrm{IC}_{50}$ concentration of olive, palmolein and SOs individually were 103,510 , and $252 \mu$ l, however, the values decreased significantly in combination with the chia oil in their blends and were 64.94, 33.78, and 26.23, respectively (Table 1). Further, in the trypan blue assay in MCF-7 cells, CSO alone showed the highest inhibition of proliferation (up to $47 \%$ ) (Fig. 7). The antiproliferation activity of $\mathrm{OlO}$ alone was not changed in combination with chia oil. However, the protective activity of PO was enhanced in combination with CSO (up to $39 \%$ ). In totality, the anticancer property of chia oil and its blending with vegetable oils suggest a potent therapeutic role as a functional food for chia in the futuristic dietary approach.

Dietary PUFAs have been attributed numerous health benefits if consumed on a regular basis. Scientific reports strongly suggest the beneficial effects of chia on human health owing to its high PUFA content. Interestingly in an isolated study, feeding hens with chia resulted in eggs with highest ALA content when compared to hens fed with linseed or rapeseed [30]. In addition, rats fed on chia seed rich diet demonstrated a decrease in low-density lipoprotein and serum

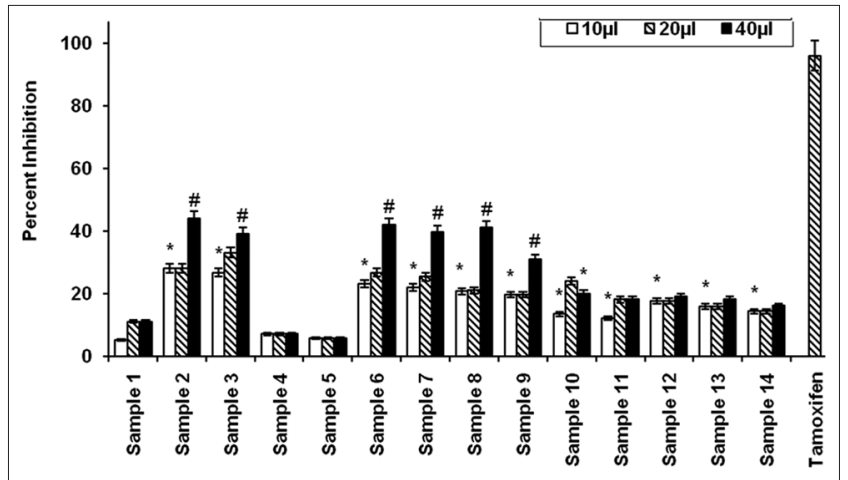

Fig. 7: Cytotoxic effects of oil samples against MCF-7 cells in vitro ( $48 \mathrm{hr}$ exposure, Trypan blue exclusion method). Values are mean \pm standard deviation $(n=3$ replications for each sample and concentration) analyzed by one-way ANOVA followed by post-hoc Tukey's test. Data are pooled from three independent experiments $(*$, \# and $\$$ indicate significant difference at $\mathbf{p} \leq 0.05)$

triglycerides, in contrast, high-density lipoprotein and n-3 PUFA levels were elevated [31]. It was also observed that no adverse effects were observed on the rat's thymus and IgE serum level. In a similar study, pigs and rabbits fed with chia seeds resulted in an increased of PUFA content, flavor and aroma in the meat fats [32]. At present, a major part of dietary PUFA is obtained from marine sources. However, the psychological stigma of people about biomagnification of some heavy metals and pesticides in addition to the disapproving odor, hinder them from consuming the fish based supplements. Moreover, a typical organoleptic characteristic such as flavor and smell from marine sources were not found in chia making it a desirable vegetable source for PUFA since ALA is converted enzymatically to PUFA in vivo [31]. In addition, global conscience about the vegetarian diet has compelled the food industry to watch out for vegetable sources of the n-3 PUFA. Thus, the excellent biological activities prove a better market presence for chia and make chia a prime candidate as a health supplement for improving the food quality.

Our study clearly demonstrates the potent anticancer property of CSO as estimated with reduced MTT reduction among CM leukemia, HeLa, and MCF-7 cells. In addition, the anti-inflammatory property of CSO and its blends was confirmed with the inhibition of LOX in vitro. Our results provide evidence that $\mathrm{CSO}$ alone or in combination with the vegetable oils proves to be a healthy synergistic supplement or an adjuvant for this diet. The supplementation with CSO is suggested for the modern lifestyle and the unhealthy diet to delay or prevent the incidence of degenerative disorders among humans.

\section{ACKNOWLEDGMENT}

The author Dr. Ramzi Abdulrashed abdulkhaleq Gazem expresses his thanks to IBB University, Yemen, for the financial assistance and to Scintilla BIO-MARC Pvt. Ltd, Bengaluru, India, for cell culture assistance.

\section{REFERENCES}

1. Donaldson MS. Nutrition and cancer: A review of the evidence for an anti-cancer diet. Nutr J 2004;3(19);19.

2. Rossi RE, Pericleous M, Mandair D, Whyand T, Caplin ME. The role of dietary factors in prevention and progression of breast cancer. Anticancer Res 2014;34(12):6861-75.

3. Laviano A, Rianda S, Molfino A, Rossi Fanelli F. Omega-3 fatty acids in cancer. Curr Opin Clin Nutr Metab Care 2013;16(2):156-61.

4. Fabian CJ, Kimler BF, Hursting SD. Omega-3 fatty acids for breast cancer prevention and survivorship. Breast Cancer Res 2015;17:62.

5. Berquin IM, Edwards IJ, Chen YQ. Multi-targeted therapy of cancer by omega-3 fatty acids. Cancer Lett 2008;269(2):363-77.

6. Puneeth HR, Sharada AC. Hypolipidemic activities of a series of pyrazoles of curcumin. IOSR J Pharm Biol Sci 2016;11(4):4-8. 
7. Puneeth HR, Ananda H, Kumar KS, Rangappa KS, Sharada AC. Synthesis and antiproliferative studies of curcumin pyrazole derivatives. Med Chem Res 2016;25(9):1842-51.

8. Ramzi GA, Puneeth HR, Sharada AC. Hypolipidemic, hypoglycemic and antiproliferate properties of chia seed oil and its blends with selected vegetable oils. An in-vitro study. IOSR J Biotechnol Biochem 2016;2(4):33-9.

9. Ramzi GA, Puneeth HR, Madhu CS, Sharada AC. Physicochemical properties and in-vitro anti-inflammatory effects of Indian chia (Salvia hispanica L.) seed oil. IOSR J Pharm Biol Sci 2016;11(2):1-8.

10. Puneeth HR, Sharada AC. Antidiabetic effects of a series of curcumin pyrazoles in-vitro. Asian J Pharm Clin Res 2015;8(6):146-9.

11. Ramzi GA, Puneeth HR, Madhu CS, Sharada AC. Antagonistic effects of combination of flaxseed oil and Spirulina platensis oil on their biological properties. Int J Pharm Pharm Sci 2015;7(1):122-7.

12. Puneeth HR, Sharada AC. Antioxidant and hypoglycemic effects of curcumin pyrazole derivatives. Int J Pharm Pharm Sci 2015;7(4):244-9.

13. Devi PU, Sharada AC, Solomon FE. In vivo growth inhibitory and radiosensitizing effects of with a ferin a on mouse Ehrlich ascites carcinoma. Cancer Lett 1995;95(1-2):189-93.

14. Devi PU, Solomon FE, Sharada AC. In vivo tumor inhibitory and radio sensitizing effects of an Indian medicinal plant, Plumbago rosea on experimental mouse tumors. Indian J Exp Biol 1994;32(8):523-8.

15. Sharada AC, Solomon FE, Devi PU. Toxicity studies on the root of Withania sominifera in rats/mice. Int J Pharm 1993;31(3):205-12.

16. Chandru H, Sharada AC, Bettadaiah BK, Kumar CS, Rangappa KS, Jayashree K. In vivo growth inhibitory and anti-angiogenic effects of synthetic novel dienone cyclopropoxy curcumin analogs on mouse Ehrlich ascites tumor. Bioorg Med Chem 2007;15(24):7696-703.

17. Sharada AC, Solomon FE, Devi PU, Udupa N, Srinivasan KK. Antitumor and radio sensitizing effects of with a ferin a on mouse Ehrlich ascites carcinoma in vivo. Acta Oncol 1996;35(1):95-100.

18. Kumar V, Bhat ZA, Kumar D, Khan NA, Chashoo IA. Evaluation of anti-inflammatory activity potential of leaf extracts of Skimmia anquetilia. Asian Pac J Trop Biomed 2012;2(8):627-30.

19. Srivastava $M$, Nambiar M, Sharma S, Karki SS, Goldsmith G, Hegde $\mathrm{M}$, et al. An inhibitor of non homologous end-joining abrogates double-strand break repair and impedes cancer progression. Cell 2012;150(7):1474-87.

20. Félix-Silva JU, Gomes JA, Barbosa LM, Pinheiro IT, Soares LA, Silva-Júnior AA, et al. Systemic and local anti-inflammatory activity of aqueous leaf extract from Jatropha gossypiifolia L. (Euphorbiaceae). Int J Pharm Pharm Sci 2014;6(6):142-5.

21. Sidambaram RR, Dinesh MG, Jayalakshmi ET. An in-vitro study of cytotoxic activity of Euphorbia hirta on hep 2 cells of human epithelioma of larynx. Int J Pharm Pharm Sci 2011;3(3):101-3.

22. Ramzi AG, Sharada AC. Omega fatty acids in health and disease: A review. J Pharm Res 2014;8(8):1027-44.

23. Simopoulos AP. Overview of evolutionary aspects of n-3 fatty acids in the diet. World Rev Nutr Diet 1998;83:1-11.

24. Creus R, Ferreira MR, Oliva ME, Lombardo YB. Mechanisms involved in the improvement of lipotoxicity and impaired lipid metabolism by dietary $\alpha$-linolenic acid rich Saliva hispanica L (salba) seed in the heart of dyslipemic insulin-resistant rats. J Clin Med 2016;5(2):E18.

25. Coorey R, Novinda A, Williams H, Jayasena V. Omega-3 fatty acid profile of eggs from laying hens fed diets supplemented with chia, fish oil, and flaxseed. J Food Sci 2015;80(1):S180-7.

26. Coorey R, Tjoe A, Jayasena V. Gelling properties of chia seed and fluor. J Food Sci 2014;79(5):E859-66.

27. Ayerza R Jr, Coates W. Effect of dietary alpha-linolenic fatty acid derived from chia when fed as ground seed, whole seed and oil on lipid content and fatty acid composition of rat plasma. Ann Nutr Metab 2007;51(1):27-34.

28. Ferrari M, Fornasiero MC, Isetta AM. MTT colorimetric assay for testing macrophage cytotoxic activity in vitro. J Immunol Methods 1990;131(2):165-72.

29. Rosangkima G, Jagetia GC. In vitro anticancer screening of medicinal plants of Mizoram state, India, against daltons lymphoma, MCF-7 and HeLa cells. Int J Rec Sci Res 2015;6:5648-53.

30. Antruejo A, Azcona JO, Garcia PT, Gallinger C, Rosmini M, Ayerza R, et al. Omega-3 enriched egg production: The effect of $\alpha$-linolenic $\omega-3$ fatty acid sources on laying hen performance and yolk lipid content and fatty acid composition. Br Poult Sci 2011;52(6):750-60.

31. Ayerza R, Coates W, Lauria M. Chia seed (Salvia hispanica L.) As an n-3 fatty acid source for broilers: Influence on fatty acid composition, cholesterol and fat content of white and dark meats, growth performance, and sensory characteristics. Poult Sci 2002;81(6):826-37.

32. Coates W, Ayerza R. Chia (Salvia hispanica L.) Seed as an n-3 fatty acid source for finishing pigs: Effects on fatty acid composition and fat stability of the meat and internal fat, growth performance, and meat sensory characteristics. J Anim Sci 2009;87(11):3798-804. 